\title{
Experimental and numerical studies on punching shear strength of concrete slabs containing sintered fly ash aggregates
}

\author{
Ranjith Babu B (Main and Corresponding Author) \\ Department of Civil Engineering, PSNA College of Engineering and Technology \\ Dindigul 624622, Tamil Nadu (India) \\ ranjithbabucivil@psnacet.edu.in \\ https://orcid.org/0000-0002-4690-7834
}

\author{
Thenmozhi R \\ Department of Civil Engineering, Government College of Technology \\ Coimbatore 641013, Tamil Nadu (India) \\ drthenmozhi@gct.ac.in \\ https://orcid.org/0000-0003-4808-4189
}

\author{
Manuscript Code:13898 \\ Date of Acceptance / Reception: 03.02.2021/12.05.2020 \\ DOI: $10.7764 /$ RDLC.20.1.15
}

\begin{abstract}
This paper presents experimental and numerical investigations on M30 grade of concrete containing $40 \%$ of sintered fly ash aggregates (SFAs) on the punching behaviour of reinforced concrete (RC) slabs. Two $1000 \times 1000 \times 100 \mathrm{~mm}$ reinforced concrete slabs were cast and subjected to punching tests. The experimental results were compared with creating a nonlinear finite element programme using ABAQUS. These 3D Finite element analyses were performed with the appropriate modelling of element size and the constitutive modelling of concrete. The material parameters of the damaged plasticity model in ABAQUS were calibrated based on the test results of the slab - plate connection. The comparison between experimental and numerical results indicates that the calibrated model correctly predicts the punching shear response of the slabs. A modification of 0.4 is introduced in MC2010 code.
\end{abstract}

Keywords: sintered fly ash aggregates (SFAs), reinforced concrete slabs, finite element analysis, ABAQUS.

Introduction

The punching shear is a failure mechanism in structural members like slabs and foundation by shear under the action of concentrated loads. When the total shear force exceeds the shear resistance of the slab, the slab will be pushed down around the column. This action was termed as punching failure. Yavum yardim \& Mehmet Alpaslan Koroglu, 2020 made a flexural study on connection between precast ferrocement panel and beam. Carmo, Costa \& Rodrigues, 2016 carried out work on punching shear strength of concrete slabs containing expanded clay aggregates. They reported that concrete containing light weight aggregates (LWA) improve the interfacial transition zone (ITZ) and also improve the stress transferring capacity. (Manu \& Dinakar, 2018) compared the characteristic of ITZ for the concrete containing Granite aggregates and sintered fly ash aggregates. The results show that the ITZ formed in SFA concrete was denser than, concrete made with granite aggregates. LightWeight aggregate concrete (LWAC) is a versatile construction material (Prakash, Thenmozhi, Raman, Subramanian \& Divyah, 2020), and the only perceived limitation of the LWAC is that it requires lightweight aggregates manufactured in industries.

Therefore the use of artificial aggregates has shown reasonable costs and produce better quality compared to conventional aggregates (Prakash, Thenmozhi, Raman \& Subramanian, 2020). The Artificial neural networking (ANN) can be used to identify the strength of the concrete mixtures having sintered fly ash aggregates (Nagarajan, Rajagopal, Meyappan, 2020). The sintered fly ash aggregate (SFA) proves to be a consistent and better construction material (Sivakumar, Gomathi (2015)). Patel, Majhi, Satpathy \& Nayak, 2019 has worked on the effect of partial replacement of coarse aggregate with SFAs. The development of lightweight concrete starts from when the partial replacement of 50 $\%$ SFA with granite aggregates. Sintered fly ash aggregate concrete (SFAC) was more suitable for the structures exposed to sulphate and chloride environments (Divyah,Thenmozhi \& Neelamegam, 2020). Hasan \& Turan, 2013; Ranjith \& Thenmozhi, 2018 has carried out a work on concrete produced with 40\% (by weight) partial replacement of fly ash aggregates with granite aggregates possess an increase in workability and doesn't show any segregation (Divyah,Thenmozhi,Neelamegam \& Prakash, 2020).

Jiangpeng, et al. (2017) used finite element analysis to know the failure propagation of concrete and steel yielding in the reinforced concrete slabs to know the punching shear force. (Andri, et al., 2019; Novarro, et al., 2018) were analyzed the punching shear strength for a slab to correlate the design equations used by critical shear crack theory and $\mathrm{ACl}$ 
codes. To verify structural failure modes, a finite element tool was helpful (Divyah, et al., 2020). The punching shear values were compared by MC2010 code and finite element simulation to verify the punching shear experimental values and failure patterns (Nuno, et al., 2015).

\section{Description of the problem}

Researchers and academicians were only focused on the suitability of concrete containing SFA. They might have been taught that the behaviour, failure pattern and the punching load were similar to the normal concrete. Therefore, concrete containing SFA has to be assessed properly for designing the structural member like beam and slab to avoid shear failure.

\section{State of the art}

Punching shear value and its failure behaviour of reinforced concrete slab were identified by experimental test results only in a few decades before, this will lead to time increasing phenomena, and the testing requires creating the test setup. Even though the concrete failure modes were relevant to its compressive strength of the mixtures. Concrete constituents were modified by partial replacement of materials such as pozzolanic or replacing the aggregate phase for the increased strength. These modified concrete constituents were further evaluated for shear, bending and torsional failures. Here, normal concrete subjected to punching failure mode was compared with an equivalent grade of concrete contains artificial sintered fly ash aggregates (40\% weight). To assess this type of changed concrete constituents behaviour ABAQUS software was used.

Methodology

\section{Materials and test specimens}

Two main materials were used in the experimental programme: concrete and steel. For concrete production Ordinary Portland Cement (OPC) 53 grade of cement (BIS:12269,2013), fine aggregate having a specific gravity of 2.64 and fineness modulus of 2.54. The maximum size of fine aggregates was limited to $4.75 \mathrm{~mm}$ (BIS:383,2016). Two coarse aggregates were used one was granite aggregates, and another one was sintered fly ash aggregates limited to $12.5 \mathrm{~mm}$. Mix design was made by trial and error procedure to achieve a target compressive strength of M30 grade (BIS:10262,2009). To avoid the excess absorption of water, the aggregates were soaked in water for $24 \mathrm{hrs}$ before concreting to reach the surface saturated dry (SSD) condition (Prakash, Thenmozhi, Raman, 2019). Conplast SP 430 was used for maintaining the workability, and a laboratory supply water was used to produce the concrete mixes.

The material properties of the tested slabs are presented in Table 1. The compressive strength (BIS: 516,1979$)$ was found from the concrete cubes $(100 \times 100 \times 100 \mathrm{~mm})$, tested at the time of slabs tests over 28 days and tensile strength (BIS: 5816,1970) was obtained from the splitting of cylinder (100 mm diameter \& $200 \mathrm{~mm}$ height) over 28 days. The reinforcement was provided at the bottom of the slabs, having $10 \mathrm{~mm}$ diameter as a main and distribution bars. No shear reinforcement was provided. The bars provided as main and bottom bars will have the same yield strength. The slabs were failed by punching alone.

\begin{tabular}{ccccc} 
Table 1. Material properties of the tested slab. (Self - Elaboration). & Young's modulus \\
Slab ID & $\begin{array}{c}\text { Compressive strength of } \\
\text { concrete (MPa) }\end{array}$ & $\begin{array}{c}\text { Tensile strength } \\
\text { of concrete (MPa) }\end{array}$ & $\begin{array}{c}\text { Y the concrete } \\
\text { (MPa) }\end{array}$ & $\begin{array}{c}\text { and distribution bars } \\
\text { (MPa) }\end{array}$ \\
\hline SFA40 & 40.93 & 3.92 & 28250 & 500 \\
\hline
\end{tabular}

SFA40 indicates $40 \%$ of sintered fly ash aggregates in concrete coarse aggregate weight.

\section{Mix details}

The mix details of the concrete mixes containing $40 \%$ of sintered fly ash aggregates were listed in Table 2 . The slump value of the concrete mix was calculated by the laboratory slump cone of $175 \mathrm{~mm}$. The increased slump was due to the presence of rounded sintered fly ash aggregate in concrete (Ranjith Babu \& Thenmozhi, 2018). 


\begin{tabular}{|c|c|c|c|c|c|c|}
\hline \multicolumn{7}{|c|}{ Table 2. Mix volume. (Self - Elaboration). } \\
\hline Mix ID & $\begin{array}{c}\mathrm{C} \\
\left(\mathrm{kg} / \mathrm{m}^{3}\right)\end{array}$ & $\begin{array}{c}F A \\
\left(\mathrm{~kg} / \mathrm{m}^{3}\right)\end{array}$ & $\begin{array}{c}\mathrm{GA} \\
\left(\mathrm{kg} / \mathrm{m}^{3}\right)\end{array}$ & $\begin{array}{c}\text { SFA } \\
\left(\mathrm{kg} / \mathrm{m}^{3}\right)\end{array}$ & $\begin{array}{l}\text { SP } \\
(\%)\end{array}$ & $\begin{array}{l}W / C \\
\text { Ratio }\end{array}$ \\
\hline SFA40 & 435 & 891.5 & 582 & 388 & $2 \%$ & 0.35 \\
\hline
\end{tabular}

\section{Punching shear on slabs (specimen description, instrumentation and results)}

Two numbers of RC slab specimens were subjected to punching test, and their size was set to stimulate the area around a column. The steel reinforcement was designed to promote only punching failure instead of flexural failure. No specific punching reinforcement was used. The clear cover was $15 \mathrm{~mm}$, the punching shear strength of slabs were assessed by an experimental setup, as shown in Figure.1. The slab specimens were cast using plywood formwork and were demoulded after two days. The slabs were then subjected to jute bag curing by spraying water once in a day, until the date of testing, 28 days. In this test, the slabs were failed by punching alone. This setup was widely used to test the flat slabs by many researchers (Fethi \& Anil, 2016).

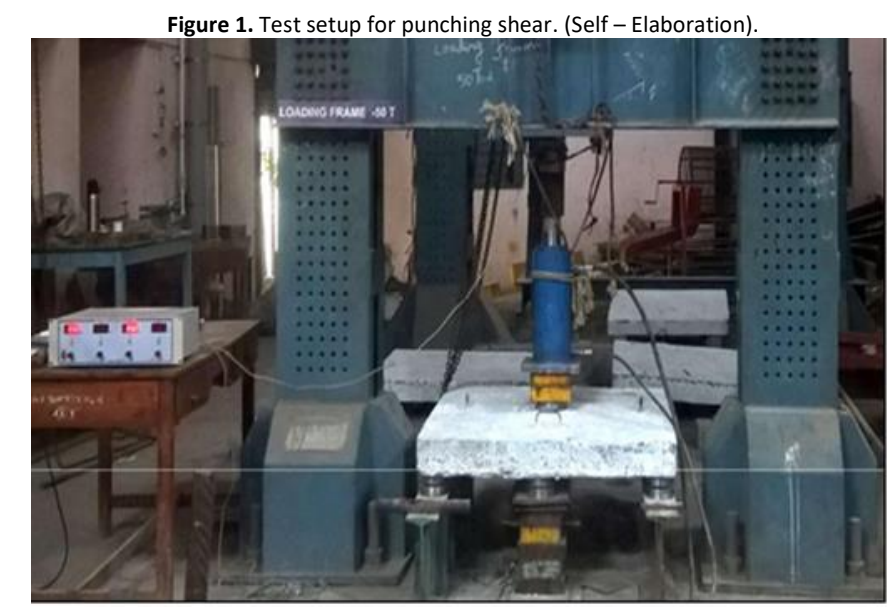

A vertical point load was applied with hydraulic jack (capacity of 50 tonnes) connected on a steel reaction frame. A circular plate of $150 \mathrm{~mm}$ diameter and $20 \mathrm{~mm}$ thick was placed below the jack to stimulate as a column action. Around the slab eight roller supports were placed at a distance of $50 \mathrm{~mm}$ from all the sides. The applied load was recorded manually by seeing the digital display with a constant interval of $5 \mathrm{kN}$, simultaneously the deflection under load was also noted. The crack patterns were observed visually; the photographs of the ultimate load crack patterns were taken. The SFA40 reinforced slabs average punching shear strength, and maximum deflections were shown in Table 3 . The failure crack pattern of sintered fly ash aggregate concrete slabs was shown in Figure 2.

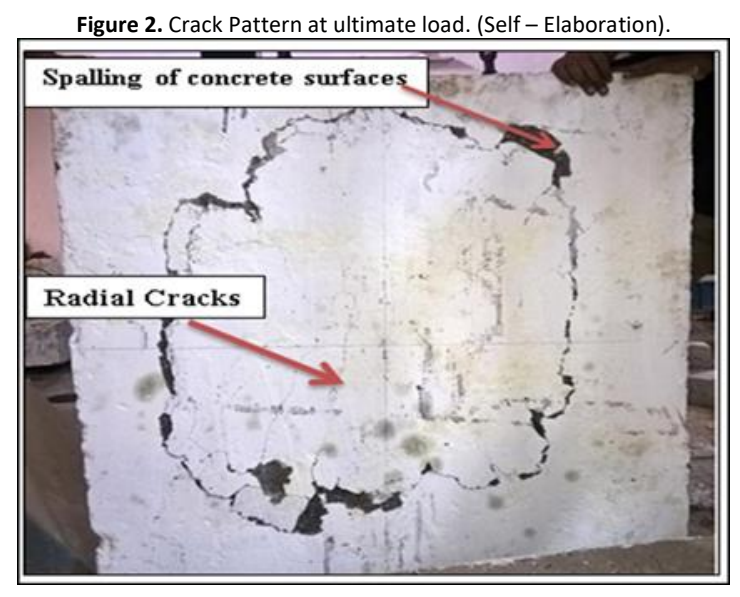


Table 3. Punching shear strength of slabs. (Self - Elaboration).

\begin{tabular}{lcccc}
\hline Specimen & $\begin{array}{c}\text { Punching Shear } \\
(\mathrm{kN})\end{array}$ & $\begin{array}{c}\text { Ultimate Deflection } \\
(\mathrm{mm})\end{array}$ & $\begin{array}{c}\text { Average Punching } \\
\text { Shear } \\
(\mathrm{kN})\end{array}$ & $\begin{array}{c}\text { Average Ultimate } \\
\text { Deflection } \\
(\mathrm{mm})\end{array}$ \\
\hline SFA40 - 1 & 127 & 4.1 & 128.5 & 3.9 \\
SFA40 - 2 & 130 & 3.7 & & 3.9 \\
\hline
\end{tabular}

Finite element simulation

\section{Methodology}

In the finite element programme (ABAQUS), the element plays an important role. To avoid shear locking effect concrete, steel reinforcement and loading disc were modelled as solid3D, 8- noded hexahedral brick elements (C3D8R) (ABAQUS, 2014; Aikaterini \& Maria, 2015). The assembly part consists of 24664 nodes and 16672 elements. The embedded method was used to simulate the bond between concrete and steel bars by considering perfect bonding. A tie was made between the bottom of the loading disc and the concrete surface to transfer the load to the concrete element.

The boundary conditions (simply supported) were applied at the eight places were the experimental test up exact matches ( 4 no's on $50 \mathrm{~mm}$ from all the four sides and another four no's on $450 \mathrm{~mm}$ at the centre edges of the slab). The 3D model was created by the ABAQUS, as shown in Figure.3. An experimental incremental load of $5 \mathrm{kN}$ was applied in the form of pressure at the top of the steel disc, to know the load-deflection response. There are three constitutive models for simulating the behaviour of concrete. Among, the concrete damage plasticity (CDP) was widely used (Aikaterini, Genikomosou \& Maria, 2015). In this present study, the CDP was calibrated by means of Dilation angle $(\psi)$, The shape factor $\left(\mathrm{K}_{\mathrm{c}}\right)$, stress - ratio $(\mathrm{fbO} / \mathrm{fc} 0)$ and eccentricity $(\epsilon)$.

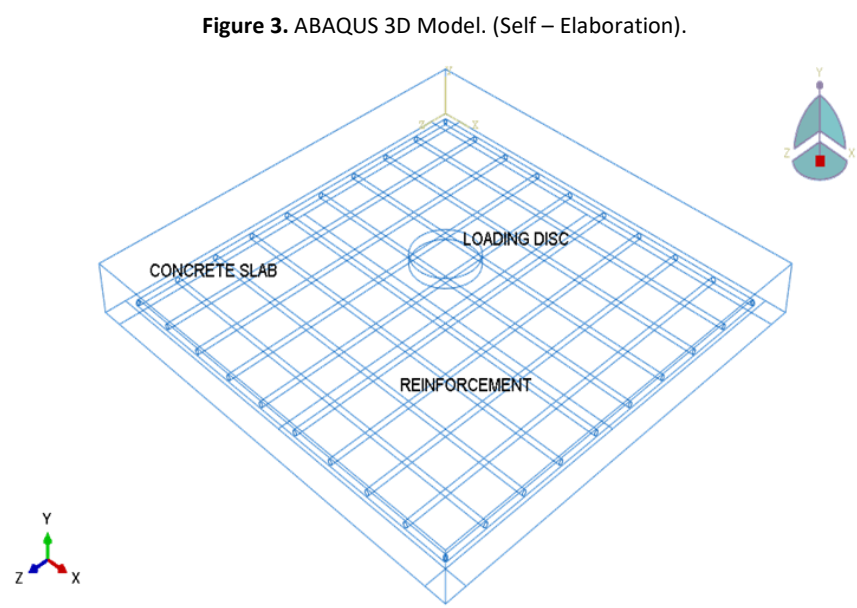

\section{Material modelling}

In material modelling, two materials were used one was concrete and another one steel in forms of rebars and loading disk. The parameters used to define those materials were based on elastic, plastic values and damage parameters.

\section{Concrete modelling parameters}

To define a model for concrete in ABAQUS, concrete has to be defined by yield stress, yield strain and corresponding compressive as well as tension damage parameters. Based on the literature reviews, concrete compressive stress-strain curve and concrete tension stress-strain curve has to be generated. To generate a compressive stress-strain curve, a uniaxial compressive test has to be done on $150 \mathrm{~mm}$ diameter and $300 \mathrm{~mm}$ height cylindrical specimen. To generate tension stress-strain curve, a split tensile test has to be done on a $100 \mathrm{~mm}$ diameter and $200 \mathrm{~mm}$ height cylindrical specimen. The tension stiffening curve was linear up to the split tensile strength value after that the descending branch was identified by the softening process. The tension stiffening was modelled by bilinear stiffening response (ABAQUS, 2014). The summarized test values used for concrete parameters were shown in Table 4. 
Table 4. SFA40 concrete parameters used in ABAQUS. (Self - Elaboration)

\begin{tabular}{|c|c|c|c|}
\hline Mix ID & $\begin{array}{l}\text { Density } \\
\left(\mathrm{kg} / \mathrm{m}^{3}\right)\end{array}$ & Young's modulus $\left(\mathrm{N} / \mathrm{mm}^{2}\right)$ & $\begin{array}{l}\text { Poisson } \\
\text { ratio }\end{array}$ \\
\hline SFA40 & 2400 & 28250 & 0.13 \\
\hline \multicolumn{4}{|c|}{ Plasticity, compressive and tensile behavior } \\
\hline $\begin{array}{c}\text { Dilation angle } \\
(\Psi)\end{array}$ & $\begin{array}{l}\text { Eccentricity } \\
(\epsilon)\end{array}$ & $\begin{array}{c}\text { Shape factor } \\
\left(K_{c}\right)\end{array}$ & $\begin{array}{c}\text { Viscosity } \\
\text { parameter }(\mu)\end{array}$ \\
\hline 50 & 0.1 & 0.667 & 0.025 \\
\hline $\begin{array}{l}\text { Compressive yield } \\
\text { stress, damage }\end{array}$ & $\begin{array}{l}\text { Inelastic } \\
\text { strain }\end{array}$ & $\begin{array}{c}\text { Compressive yield stress, } \\
\text { damage }\end{array}$ & $\begin{array}{l}\text { Inelastic } \\
\text { strain }\end{array}$ \\
\hline $20.37,0$ & 0.00072 & $27.162,0.19$ & 0.00128 \\
\hline $21.5,0.03$ & 0.00080 & $28.29,0.22$ & 0.00140 \\
\hline $22.63,0.06$ & 0.00088 & $29.42,0.30$ & 0.00168 \\
\hline $23.76,0.09$ & 0.00096 & $30.55,0.34$ & 0.00188 \\
\hline $24.89,0.11$ & 0.00104 & $31.68,0.37$ & 0.00208 \\
\hline $26.03,0.15$ & 0.00116 & $32.82,0.40$ & 0.00228 \\
\hline \multicolumn{2}{|c|}{ Tensile yield stress, damage } & \multicolumn{2}{|c|}{ Cracking strain } \\
\hline \multicolumn{2}{|c|}{$3.92,0$} & \multicolumn{2}{|c|}{0.00014} \\
\hline \multicolumn{2}{|c|}{$3.01,0.30$} & \multicolumn{2}{|c|}{0.00121} \\
\hline \multicolumn{2}{|c|}{$1.76,0.84$} & \multicolumn{2}{|c|}{0.00056} \\
\hline \multicolumn{2}{|c|}{$0.39,0.98$} & \multicolumn{2}{|c|}{0.00017} \\
\hline
\end{tabular}

The damage behaviour of the SFA40 concrete was considered by laboratory tested stress-strain readings; the compressive plastic strain was calculated by using ABAQUS manual. The tensile stress and tensile strains were calculated by considering modified stress and strain values used by (Wahalathantri, Thambiratnam, Chan \& Fawzia, 2011; ABAQUS, 2014). The compressive and tensile damages were shown in Figure 4 and Figure 5.

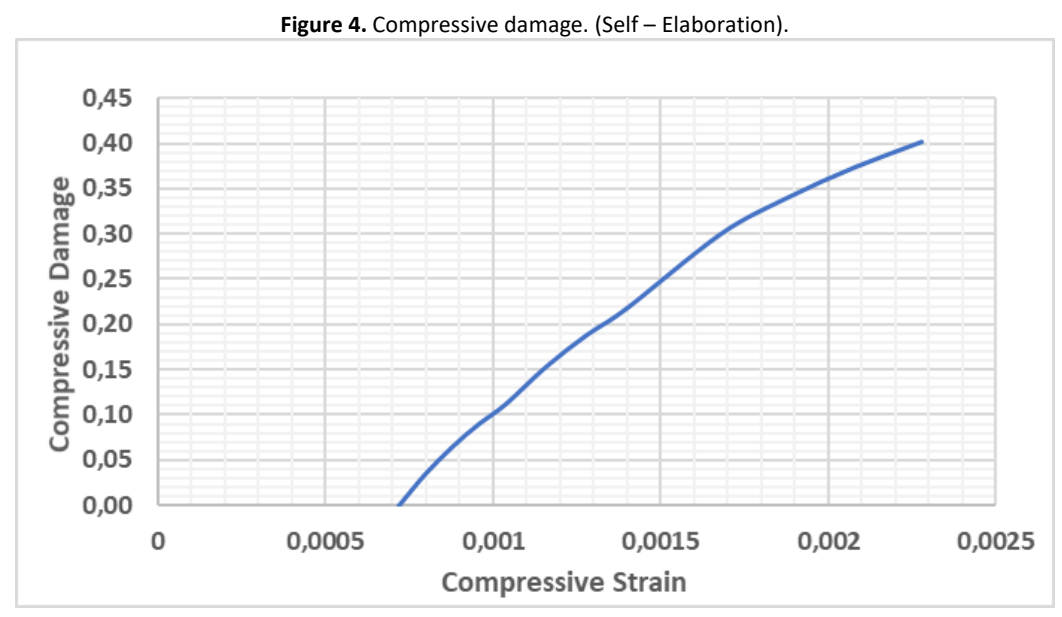




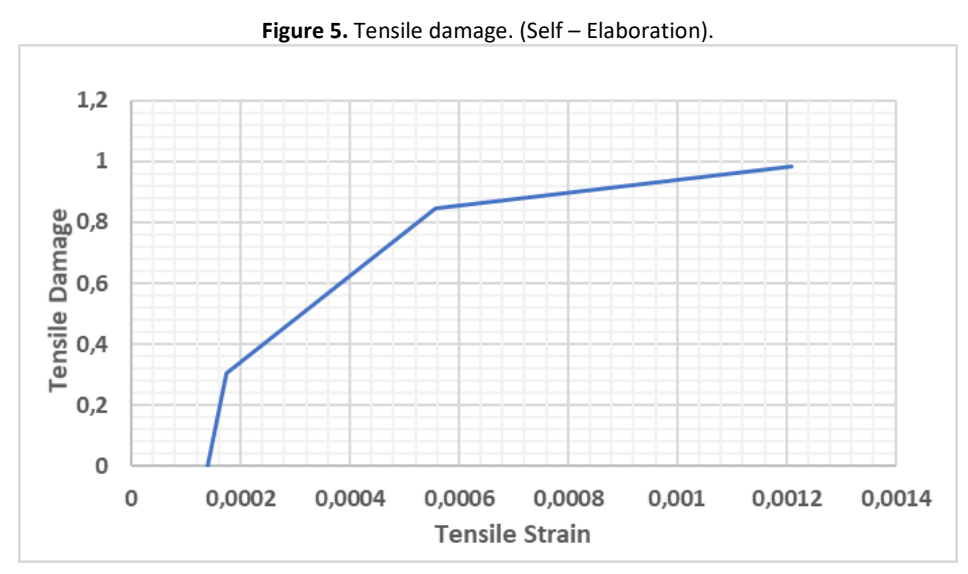

\section{Rebar modelling parameters}

The steel rebars were modelled as elastic with Young's modulus $\left(E_{s}\right)$ and Poisson ratio $\left(U_{s}\right)$ of having a typical value of 200,000 MPa and 0.3, respectively. The plastic properties were defined based on the test results with a bilinear strain hardening yield stress - plastic strain curve. The yield strength of the bars used in the slabs were Fe500 twisted bars. The properties of the steel bar were tabulated in Table 5.

\begin{tabular}{cccc}
\multicolumn{4}{c}{ Table 5. Rebar parameters used in ABAQUS. (Self - Elaboration). } \\
\hline Yield stress (MPa) & Inelastic strain & Yield stress (MPa) & Inelastic strain \\
\hline 400 & 0 & 475 & 0.0007 \\
425 & 0.0001 & 487.5 & 0.0010 \\
450 & 0.0003 & 500 & 0.0020 \\
\hline
\end{tabular}

\section{Loading disc modelling parameters}

In the ABAQUS modelling loading disc was modelled as an elastic material by giving the Density ( $\rho$ ), Young's modulus $\left(E_{s}\right)$ and poisons ratio $\left(U_{s}\right)$ of having a typical value of $7850 \mathrm{~kg} / \mathrm{m}^{3}, 200,000 \mathrm{MPa}$ and 0.3 , respectively. In the real experimental test, while applying the load to the slab, the disk just acts as a transferring medium. So, it has to be modelled in the form of elastic material.

\section{Type of analysis used in ABAQUS}

After successful completion of the modelling, the type of analysis has to be understood properly, the slab was experiencing a punching action by the loading disc. The analysis was identified by quasi-static analysis due to the action of punching. To perform this quasi-static analysis in ABAQUS, a linear permutation step has to be done by identifying the failure mode shape as well as the time period to complete the job. The identified time period was 0.00167 . The assumed mode shape failure was shown in Figure 6. The calculated time period was based on corresponding mode shape frequency $(595.68$ cycles/sec) by using a basic time period and frequency relationship as given in equation 1.

$$
\text { Frequency }(f)=\frac{1}{\text { Time period }(T)}
$$




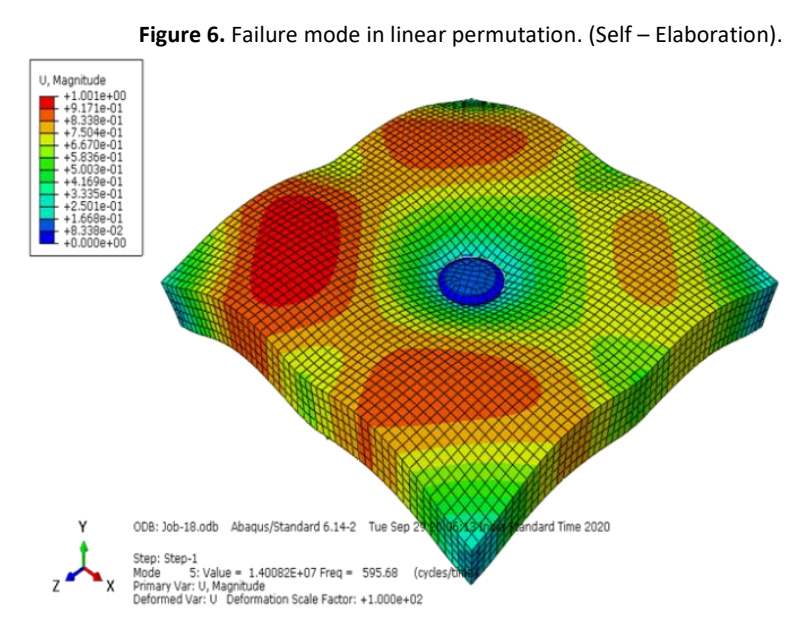

\section{Calibration of the model}

The calibration of the slab was based on expecting the same load-deflection response from the tested load-deflection values. Infinite element analysis, calibration is the necessary condition to compare the tested behaviour. Once the model was calibrated, then the model can use for parametric analysis. A parametric analysis, on the flat slab subjected to punching load, has to be done for understating the factors which would increase the shear (Novarro, Ivorra \& Varona, 2018). Here the tested slab was modelled and calibrated by means of plasticity values.

The size of the mesh was kept as $20 \mathrm{~mm}$ for better results (Aikaterini \& Maria, 2015). For accurate modelling, the dilation angle has to be properly calibrated (Genikomosou \& Maria, 2015). The load-deflection chart was made by taken from the node which attains maximum reaction values (RF2), and the deflection value was taken from the bottom of the slab at the centre at the node 1326 from the visualization window. The dilation angle varies from $40^{\circ}$ to $50^{\circ}$. The loaddeflection values for various dilation angles and viscosity values were shown in Figure 7.

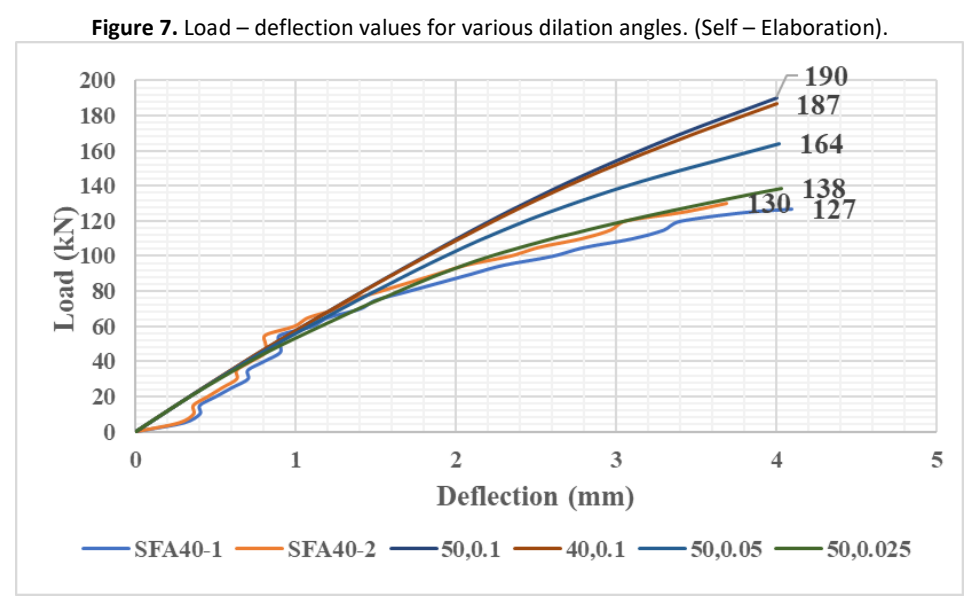

The dilation angle $50^{\circ}$ was matched with experimental load-deflection values, another plasticity parameters such as eccentricity, shape factor and stress ratio values were not able to vary, because these parameters were calibrated by many researchers (Aikaterini \& Maria, 2015; Novarro, Ivorra \& Varona, 2018). Apart from the dilation angle, the viscosity parameters were varied with the values of $0.1,0.05$ and 0.025 . The viscosity 0.025 and dilation angle $50^{\circ}$ provides the same load-deflection curve as an experimental pattern. The ABAQUS modelled ultimate punching shear value and its corresponding midspan deflection, as shown in Table 6. 
Table 6. ABAQUS results. (Self - Elaboration).

\begin{tabular}{ccccc}
\hline Mix ID & $\begin{array}{c}\text { Ultimate } \\
\text { punching } \\
\text { shear }(\mathrm{kN})\end{array}$ & $\begin{array}{c}\text { Midspan } \\
\text { deflection } \\
(\mathrm{mm})\end{array}$ & $\begin{array}{c}\text { Ratio between average } \\
\text { experimental and abaqus } \\
\text { Punching Shear }\end{array}$ & $\begin{array}{c}\text { Ratio between average } \\
\text { experimental and abaqus } \\
\text { midspan deflection }\end{array}$ \\
\hline SFA40 & 138 & 4 & 0.93 & 0.98 \\
\hline
\end{tabular}

\section{Comparison with international codes}

The obtained experimental result was compared with the theoretical values predicted by MC2010 (fib model code, 2013). In MC2010, the punching shear resistance is given by equation 2.

$$
V_{R}=k_{\Psi} \cdot \frac{\sqrt{f_{c k}}}{\gamma_{\mathrm{c}}} \cdot b_{o} \cdot d_{v}
$$

where,

$V_{R}=$ Punching shear strength $(\mathrm{kN})$

$k_{\Psi}=1 /\left(1.5+0.9 \mathrm{kdg}_{\mathrm{dg}} . \Psi . \mathrm{d}\right)<0.6 ; k_{d g}=\frac{32}{16+d_{g}}$

$\mathrm{d}_{\mathrm{g}}=$ maximum aggregate size in $\mathrm{mm}$;

$\Psi=1.5 \cdot \frac{r_{s}}{d} \cdot \frac{f_{y d}}{E_{S}}-$ slab rotation given by Level $-I$ of approximation;

$r_{s}=$ Position where the radial moment is zero with respect to the column axis $(\mathrm{mm})$

$d=$ Average depth of the slab ( $\mathrm{mm})$

$f_{y d}=$ Yield stress of the reinforcement $(\mathrm{MPa})$

$E_{s}=$ Elastic Modulus of steel (MPa)

$f_{c k}=$ Cubical characteristic compressive strength of the concrete at 28 days ( $\mathrm{MPa}$ )

$\gamma_{\mathrm{c}}=$ Partial safety factor for concrete (taken as 1.0)

$b_{o}=b_{1} . k_{\mathrm{e}}-$ effective control perimeter $(\mathrm{mm})$

$b_{1}=$ basic control perimeter at a distance of $d$ from the column border $(\mathrm{mm})$

$(\Pi *(150+80))=723 \mathrm{~mm}$; due to circular loading.

$\mathrm{k}_{\mathrm{e}}=$ eccentricity coefficient ( 0.9 for inner column)

$d_{v}=$ effective depth of the slab $(\mathrm{mm})$

The calculated punching shear based on MC2010 code was listed in Table 7. In this calculation, $d_{\mathrm{g}}$ has been taken as 0 $\mathrm{mm}, 0.4 \mathrm{~mm}$ and $12.5 \mathrm{~mm}$. The $d_{\mathrm{g}}$ was taken as 0 for the consideration of lightweight concrete as per MC2010 code. The $d_{g}$ was taken as 0.4 for the $40 \%$ incorporation of sintered fly ash aggregate in the concrete aggregates. The $d_{g}$ was taken as 12.5 for the maximum size of aggregate was passing on $12.5 \mathrm{~mm}$ sieve.

Table 7. Comparison between the MC2010 Level -I and the experimental collapse load. (Self - Elaboration).

\begin{tabular}{|c|c|c|c|c|c|c|c|}
\hline \multirow{2}{*}{ Mix ID } & \multirow{2}{*}{$\begin{array}{l}\text { Experimental } \\
\text { punching load } \\
(\mathrm{kN})\end{array}$} & \multicolumn{3}{|c|}{ Theoretical load MC2010 -level -I (kN) } & \multirow{2}{*}{$\begin{array}{c}\text { Ratio } P_{\text {Exp }} / \\
\begin{array}{c}P_{\text {The }} \\
\mathrm{dg}=0\end{array}\end{array}$} & \multirow{2}{*}{$\begin{array}{c}\text { Ratio P } P_{\text {Exp }} / \\
\text { PThe } \\
\text { dg }=0.4\end{array}$} & \multirow{2}{*}{$\begin{array}{c}\text { Ratio } \\
\text { P }_{\text {Exp }} / \\
P_{\text {The }} \\
\text { dg }=12.5\end{array}$} \\
\hline & & $\mathrm{dg}=0$ & $\mathrm{dg}=0.4$ & $\mathrm{dg}=12.5$ & & & \\
\hline SFA40 -1 & 127 & \multirow{2}{*}{117.20} & \multirow{2}{*}{118.53} & \multirow{2}{*}{85.71} & 1.08 & 1.07 & 1.48 \\
\hline SFA40 -2 & 130 & & & & 1.10 & 1.09 & 1.51 \\
\hline
\end{tabular}

\section{Effect of SFA concrete crack pattern with normal failure}

The failure mode of the slabs was compared with Fethi \& Anil, 2016 normal concrete tested slab failure pattern. It seems that concrete containing sintered fly ash aggregates increases cracks around the loading area compare to the normal concrete failure. The comparison between normal concrete failure and sintered fly ash aggregate concrete failures were shown in Figure 8. The failure pattern of the slab specimen in ABAQUS was shown in Figure 9. 

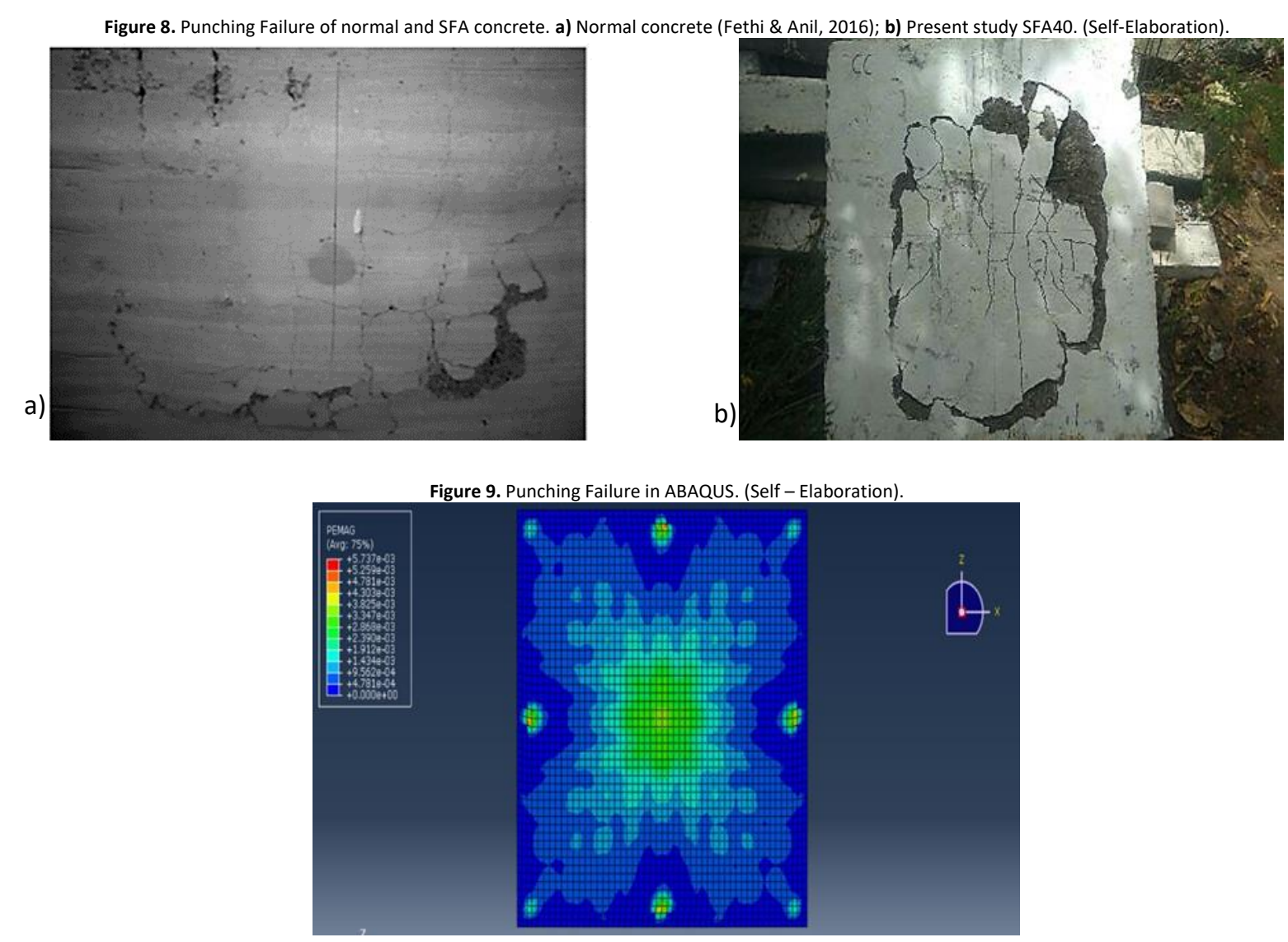

Results and discussion

The concrete contains SFA has the same behaviour compared to normal concrete, the partial replacement (40\% weight) of SFA in concrete increase the workability as well as the mechanical behaviour. The tensile strength of the concrete was identified by $1 / 10 \mathrm{X}$ compressive strength of the concrete contains SFA. The average punching shear strength from the tested RC slabs was $128.5 \mathrm{kN}$ and its average mid-span deflection was $3.9 \mathrm{~mm}$. This tested value will be used to corelate the theoretical and ABAQUS punching shear strength values.

In ABAQUS modelling, material properties play an important role. The concrete, rebar and loading disc were modelled by using the constitutive model (CDP) for concrete, elastic \& plastic values for rebar and loading disc. The results show that the CDP has an important understating in terms of compressive and tensile damage parameters. The loading nature was identified by Quasi-static loading. To know the time period, a linear permutation step has to be done. This time period corresponding frequency was based on failure mode shape.

The calibration of the model was based on dilation angle value; the most suitable value was $50^{\circ}$. Normally this dilation angle varies from $40^{\circ}$ to $50^{\circ}$ for lightweight aggregate concrete. In addition to the dilation angle value, viscosity was also varied from 0.1 to 0.025 . The best fit of the experimental load-deflection value was identified with the combination of dilation angle $50^{\circ}$ and viscosity 0.025 . Once the model was properly calibrated with the help of experimental values, this model can further used for changing parameters like reinforcement ratio, concrete strength, yield strength of the rebars and also reinforcement patterns. The ultimate displacement values obtained from ABAQUS, as shown in Figure.10. 


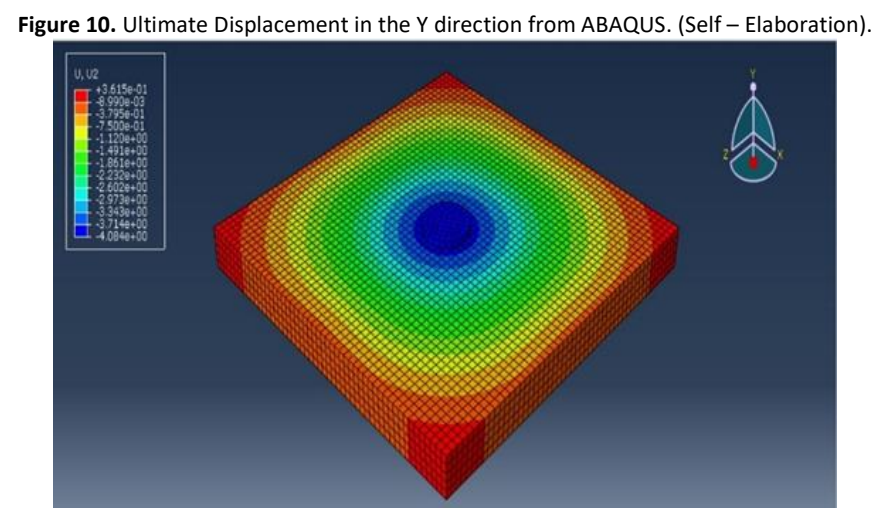

To understand the punching shear strength, the experimental values were compared with MC2010 - Level -I approximation. In this codebook, a modification was newly introduced. If $40 \%$ of SFA was used, the $d_{g}$ value was taken as 0.4. This can appropriately equal to the experimental values. The crack pattern was compared with normal concrete behaviour. It shows that the addition of SFA in concrete increase the concrete cracking and also the spalling effect. This spalling can be controlled by adding steel fibres in the concrete.

In general, increased compressive strength was directly proportional to increased punching shear strength. Addition of SFA in concrete strengthen the ITZ and also the durability due to its porous and inert reaction with siliceous products.

Conclusions

The following were the conclusions drawn from the experimental programme and numerical work:

- The addition of SFA in concrete increase the compressive, split tensile and young's modulus of the concrete.

- A time period has to be identified for the ABAQUS programme was based on failure mode shape.

- The CDP shows good agreement with the experimental results.

- $\quad$ The calibration of the model in ABAQUS highly depended on dilation angle and viscosity value.

- In further, the finite element programme can be used to analyze the model in terms of varying the strength parameters and reinforcement patterns.

- A modification was newly introduced in MC2010 - Level -I as 0.4 for $40 \%$ of SFA in concrete. This gives an understanding of SFA contribution in normal concrete.

- $\quad$ The cracks and spalling were more in concrete contains SFA. This can be overcome by adding steel fibers.

References

ABAQUS/CAE. (2014). User's manual version 6.14-2, USA.

Aikaterini S. Genikomosou., Maria Anna Polak. (2015). Finite element analysis of punching shear of concrete slabs using damage plasticity model in ABAQUS. Engineering structures, 98, 38-48. doi: 10.1016/j.engstruct.2015.04.016.

Andri Setiawan., Vollum, R. L., Macorini,L., Bassam S, Lzzuddin. (2019). Efficient 3D modelling of punching shear failure at slab - column connections by means of nonlinear joint elements. Engineering structures,197,1-19. doi: 10.1016/j.engstruct.2019.109372.

BIS 10262: 2009, Concrete Mix Proportioning - Guidelines, Bureau of Indian Standards, New Delhi, India.

BIS 12269-2013, Ordinary Portland cement, Grade: 53, Bureau of Indian Standards, New Delhi, India.

BIS 516 -1959, Indian standard, Methods of tests for strength of concrete, Bureau of Indian Standards, New Delhi, India.

BIS 5816-1970, Method of test splitting tensile strength of concrete cylinders, Bureau of Indian Standards New Delhi, India.

BIS:383(2016). Specification for coarse and fine aggregates, Bureau of Indian Standards, New Delhi, India.

Carmo, R.N.F., Costa, H., Rodrigues, M. (2016). Experimental study of punching failure in LWAC slabs with different strengths. Materials and Structures, 49, 2611-2626. doi:10.1617/s11527-015-0671-x.

Divyah, N., Thenmozhi, R., Neelamegam, M. (2020). Experimental and Numerical Analysis of Battened Built -up Lightweight concrete Encased composite columns subjected to axial cyclic loading. Latin American Journal of Solids and Structures, 17(3), 1-15. doi: 10.1590/1679-78255745. 
Divyah, N., Thenmozhi, R., Neelamegam, M., Prakash, R. (2020). Characterization and behavior of basalt fiber-reinforced lightweight concrete. Structural Concrete,1-9. doi: 10.1002/suco.201900390.

Divyah, N., Thenmozhi, R., Neelamegam,M. (2020). Strength properties and durability aspects of sintered-fly-ash lightweight aggregate concrete. Materials in Tehnologije, 54(3), 301-310. doi: 10.17222/mit.2019.101.

Nagarajan D, Rajagopal T, Meyappan N (2020). A comparative study on prediction models for strength properties of LWA concrete using artificial neural network. Revista de la construcción, 19(1), 103-111. doi:10.7764/rdlc.19.1.103-111

Fethi Sermet., Anil Ozdemir. (2016). Investigation of punching behaviour of steel and polypropylene Fiber Reinforced concrete slabs under Normal load. Procedia Engineering, 161, 458-465. doi: 10.1016/j.proeng.2016.08.590.

Fib model code for concrete structures 2010 (MC2010). (2013), ISBN: 978-3-433-03061-5, Ernst \& sohn publishing house, Switzerland.

Gomathi,P., Sivakumar,A. (2015). Accelerated curing effects on the mechanical performance of cold bonded and sintered fly ash aggregate concrete. Construction and Building Materials, 77, 276-287. doi: 10.1016/j.conbuildmat.2014.12.108.

Hasan Yildirim., Turan Ozturan. (2013). Mechanical properties of lightweight concrete made with cold bonded fly ash pellets. 2 nd International Balkans Conference on challenges of Civil Engineering, Epoka University, Tirana, Albania.

Jiangpeng Shu., Beatrice Belletti., Aurelio Muttoni., Matteo Scolari., Mario Plos. (2017). Internal force distribution in RC slabs subjected to Punching shear. Engineering structures, 153, 766-781.doi: 10.1016/j.engstruct.2017.10.005.

Manu S. Nadesan., Dinakar,P. (2018). Micro-structural behavior of interfacial transition zone of the porous sintered fly ash aggregate. Journal of Building Engineering, 16, 31-38. doi: 10.1016/j.jobe.2017.12.007.

Novarro, M., Ivorra S., Varona, F.B. (2018). Parametric computational analysis for punching shear in RC slabs. Engineering Structures. 165 , $254-263$. doi: 10.1016/j.engstruct.2018.03.035

Nuno Reis., Jorge de Brito., Joao R, Correia., Mario R.T, Arruda. (2015). Punching behaviour of concrete slabs incorporating coarse recycled concrete aggregates. Engineering Structures, 100, 238-248. doi: 10.1016/j.engstruct.2015.06.011.

Patel,S.K., Majhi,R.K., Satpathy,H.P., Nayak,A.N. (2019). Durability and microstructural properties of lightweight concrete manufactured with fly ash cenosphere and sintered fly ash aggregate. Construction and Building Materials, 226, 579-590. doi: 10.1016/j.conbuildmat.2019.07.304.

Prakash, R., Thenmozhi, R., Raman, SN. (2019). Mechanical characterisation and flexural performance of eco-friendly concrete produced with fly ash as cement replacement and coconut shell coarse aggregate. International journal of Environment and sustainable Development, 18(2), 131-148. doi: 10.1504/ IJESD.2019.099491.

Prakash,R., Thenmozhi,R., Raman, SN., Subramanian, C., Divyah,N.(2020). An investigation of key mechanical and durability properties of coconut shell concrete with partial replacement of fly ash. Structural Concrete, 1-12. doi: 10.1002/suco.201900162.

Ranjith Babu, B., Thenmozhi, R. (2018). An investigation of the mechanical properties of Sintered Fly Ash Lightweight Aggregate Concrete (SFLWAC) with steel fibres. Archives of Civil Engineering, 64(1),73-85. doi: 10.2478/ace-2018-0005.

Wahalathantri, B.L., Thambiratnam, D.P., Chan, T.H.T., \& Fawzia, S. (2011). A material model for flexural crack simulation in reinforced concrete elements using ABAQUS. In Proceedings of the First International Conference on Engineering, Designing and Developing the Built Environment for Sustainable Wellbeing, Queensland University of Technology, Queensland University of Technology, Brisbane, Qld, 260-264.

Yardim, Y., \& Koroglu, M. A. (2020). An experimental study on the performance of precast ferrocement panel for composite masonry slab systems. Revista de la Construcción. Journal of Construction, 19(3), 213-223. 